Agricultural geography as interpreted in this book embraces the systematic study of the location and distribution of agricultural enterprises giving special emphasis to approaches developed by economists and economic geographers. The authors, however, claim that all aspects of agricultural geography are reviewed, including environmental problems. No doubt the precise balance between the physical, human and economic components will vary, but in this publication the economic side receives most of the emphasis, which creates something of an imbalance. At times one needed reassurance that the title of the book was indeed "Agricultural Geography" and not "Agricultural Economics". Chapter 1, "Nature of Agricultural Geography", which devotes six pages to "Economic Concepts and Principles" against approximately two pages given to "Physical and Biological Environment" and "Cultural Constraints" respectively, illustrates the point well.

Generally, the subject matter is developed logically and well throughout the book. Chapter 8, "Government Policy", provides an admirably concise exposition outlining the influence of government activity on the spatial organization of agriculture. Modern sociological approaches together with the effect of individual psychology are introduced when discussing decision making. Agricultural activity and physical environment, including land classification, receive scant attention.

A useful introduction into the problems of data collection, classification and the relevant analytical techniques is attempted in Chapter 9. This rightly points out that many approaches result in only crude general comparisons.

The book is written in a pleasing, easy style and is attractively produced with clearly presented diagrams and tables. Agricultural Geography is a stimulating book recommended to all interested readers and libraries.

B. WILKINSON

\section{Amines and Membranes}

Biogenic Amines and Physiological Membranes in Drug Therapy. By John H. Biel and Leo G. Abood. Part A: Pp. ix +1-160. \$12.50. Part B: Pp. vii +161525. \$25.50. (Marcel Dekker: New York, November 1971.)

Books consisting of a collection of review articles written by various authors often serve a useful purpose in integrating existing facts and new ideas into an exciting whole. Some are more successful than others, however; unfor- tunately, these two volumes do not fall into the successful category. The title and the preface suggest a comprehensive coverage of effects of amines and therapeutic drugs on membranes; in fact the first book consists of four reviews on membrane structure and ATPase and on ionic movements in natural and artificial membranes, with very little correlation with either amines or therapeutic drugs, while the second has six review articles on biogenic amines, their uptake, synthesis, degradation and oxidation, with passing reference to therapy and virtually no connexion with physiological membrane properties. This lack of entity may explain why a 500page text has been split into two volumes; the potential market for each separately may be greater than that of the whole.

It is not easy to see what this potential market would be. The blurb claims it is aimed at the research scientist, physiologist or pharmacologist, the medical student or the physician in clinical pharmacology. Individual reviews could be of great use to a variety of people, but severe warnings regarding copyright preclude the use of separate articles for teaching purposes or research. The cost would deter many, particularly students, from buying the books either singly or as a pair and only a few researchers would find more than three or four of the ten reviews of vital interest to their work. Also the appearance of the publication is not attractive; the pseudo-typescript format and the excessive number of typographical or spelling mistakes would suggest a hurried, unedited production, but the paucity of references after 1969 in the majority of reviews, with the exception of the two by Creveling, Daly and colleagues, would suggest that most of them were written at least some 18 months before publication. The multitude of errors is annoying rather than confusing, however.

The individual review articles are, however, of an adequate standard. The preface expresses the hope that the book will raise as many questions as it will answer; this is noticeable in some papers by the lack of any attempt to provide definite conclusions. In volume $A$ on membranes, the article which most appealed to me, probably because it was deliberately limited in scope but therefore concentrated on one aspect, was by Bean, Shepherd and Eichner on the production and properties of excitable artificial membranes. This highlighted some of the properties of -membranes and made more relevant other more wide-reaching papers, such as the article by Abood and Matsubara on membrane structure and Tasaki's ideas on the role of cations and proposed transitions between stable membrane states in the squid axon. Volume
$B$ on amines includes updated and expanded revisions of earlier reviews by Hornykiewicz on dopamine, Iversen on biogenic amine uptake, Kopin on false transmitters and also a more limited review of histamine by Schayer. But the most interesting to me was the article by Jerina, Daly and Witkop on the molecular rearrangements occurring during enzymic oxidations, the so-called NIH shift. It is difficult to see the relevance of this paper to the rest of the book, but it assembles together and summarizes a considerable body of work around a definite topic and then suggests some ways in which further research is necessary, thus achieving concisely the objects of this type of review.

In summary, these volumes contain much worthwhile accumulated information in a series of review articles of variable quality, but as a book it lacks the cohesion and correlation necessary to make it a useful whole. It seems a pity that an excellent concept was not carried out more successfully; perhaps this is because the range of topics or the scope of the articles was too limited and production was started before sufficient conclusive evidence was available.

R. LAVERTY

\section{Low Temperatures}

Cryogenic Fundamentals. Edited by G. G. Jaselden. Pp. xiii 757 . (Academic: New York and London, October 1971.) $£ 11.50 ; \$ 33$.

IN covering the fundamental aspects of the technology of cryogenics in a unified manner over the whole temperature spectrum below about $150 \mathrm{~K}$, Cryogenic Fundamentals lives up to its name as a comprehensive textbook of over 700 pages. It is aimed to meet the requirements of engineers involved with equipment design and operation, and of research workers in cryogenic laboratories.

Looking back over the 1960 s we have witnessed a constantly changing pattern in cryogenics and a widening range of commercially viable applications. The decade has included the development of high field superconductivity from scratch; of large hydrogen-fuelled rockets like the Saturn $\mathrm{V}$ vehicles and the completion of the first Apollo lunar landing missions; of marine transportation of liquid natural gas on a large scale; of cryo-surgery and cryo-preservation techniques in medicine; of the ${ }^{3} \mathrm{He} /{ }^{4} \mathrm{He}$ dilution refrigerator for continuous refrigeration below $1 \mathrm{~K}$ down to $0.01 \mathrm{~K}$ or lower; and so on. The 1970s 